\title{
Improved antitumoral properties of pure antiestrogen RU 58668-loaded liposomes in multiple myeloma
}

\author{
Sébastien Maillard ${ }^{\mathrm{a}}$, Juliette Gauduchon ${ }^{\mathrm{b}}$, Véronique Marsaud ${ }^{\mathrm{a}}$, Fabrice Gouilleux ${ }^{\mathrm{c}}$, \\ Elisabeth Connault ${ }^{\mathrm{d}}$, Paule Opolon ${ }^{\mathrm{d}}$, Elias Fattal ${ }^{\mathrm{a}}$, Brigitte Sola ${ }^{\mathrm{b}}$, Jack-Michel Renoir ${ }^{\mathrm{a}, *}$ \\ ${ }^{\text {a }}$ CNRS UMR 8612, Université de Paris-Sud, Châtenay-Malabry, France \\ ${ }^{\mathrm{b}}$ UFR de médecine, EA3919, Université de Caen-Basse Normandie, Caen, France \\ c INSERM EMI0351, Université Jules Verne, Amiens, France \\ ${ }^{\mathrm{d}}$ CNRS UMR 8121, Institut Gustave Roussy, Villejuif, France
}

Received 7 February 2006; accepted 23 March 2006

\begin{abstract}
In most of multiple myeloma (MM) cells, the "pure" antiestrogen (AE) RU 58668 (RU) induced either a G1-arrest (LP-1, OPM-2, NCIH929, U266 cells) or apoptosis (RPMI 8226 cells). In RPMI 8226 cells, RU activates a caspase-dependent cell death pathway leading to the release of cytochrome $c$, the decrease of the essential MM survival factor Mcl-1, the cleavage of Bid and the activation of caspases-3 and -8. Incorporation of RU in pegylated cholesterol-containing liposomes allowed a controlled RU release, improving its anti-proliferative and apoptotic effects in cells. In RPMI 8226 xenografts, i.v. injected RU-liposomes but not free RU, exhibited antitumor activity. In vivo, RU-liposomes triggered the mitochondrial death pathway, concomitantly with a down-regulation of Mcl-1 and Bid cleavage. The decrease of CD34 immunoreactivity indicated a reduction of angiogenesis. The decrease of VEGF secretion in vitro supported a direct effect of RU on angiogenesis. These pro-apoptotic and antiangiogenic effects were explained by a prolonged exposure to the drug and to the endocytosis capacity of liposomes which might increase RU uptake and bypass a membrane export of free RU. Thus, these combined enhanced activities of RU-liposomes support that such a delivery of an AE may constitute a strategy of benefit for MM treatment.
\end{abstract}

(c) 2006 Elsevier Ltd. All rights reserved.

Keywords: Antiestrogen delivery; Liposomes; Myeloma; Apoptosis

\footnotetext{
Abbreviations: 4-HT, 4-hydroxytamoxifen; Ab, antibody; AE, antiestrogen; CHOL, cholesterol; DSPE-PEG ${ }^{2000}$, 1,2-distearoyl-sn-glycero-3phosphoethanolamine- $N$-[methoxy(polyethylene glycol)-2000]; $\mathrm{E}_{2}, 17 \beta-$ estradiol; EPC, egg phosphatidyl choline; ER, estrogen receptor; Mcl-1, myeloid cell leukemia-1; MM, multiple myeloma; MTS, 3-(4,5-dimethylthiazol-2-yl)-5-(3-carboxymethoxyphenyl)-2-(4-sulfophenyl)-2H-tetrazolium, inner salt; P-gp, P-glycoprotein; RU 58668, 11 $\beta-[4-[5-[(4,4,5,5,5-$ pentafluoropentyl)sulfonyl]pentyloxy]phenyl]-estra-1,3,5,(10)triene-3,17 $\beta$ diol; SERM, selective estrogen receptor modulator; TAM, tamoxifen; TUNEL, terminal deoxynucleotidyl transferase-mediated deoxyuridine triphosphate nick-end-labeling; VEGF, vascular endothelium growth factor

* Corresponding author at: UMR CNRS 8612, Pharmacologie cellulaire et moléculaire des anticancéreux, 5 rue Jean-Baptiste Clément, 92296 Châtenay-Malabry Cedex, France. Tel.: +33 146835831; fax: +33 146835832 .

E-mail address: michel.renoir@ cep.u-psud.fr (J.-M. Renoir).
}

\section{Introduction}

Multiple myeloma (MM) is an incurable B hemopathy with a median survival of $2-3$ years, characterized by plasma cells accumulating in the bone marrow and by the development of osteolytic lesions [1]. The need for efficient therapy has become obvious and a number of new agents such as antiangiogenic compounds like thalidomide and inhibitors of the vascular endothelium growth factor (VEGF), proteasome inhibitors like bortezomib, and farnesyltransferase inhibitors seem to be promising [2].

Estrogens regulate many functionally unrelated processes in numerous tissues and exert their effects on growth, development and differentiation on various cell types, through binding to their specific nuclear estrogen receptors (ERs) [3]. Moreover, estrogens are negative regulators of B-lympho- 
poiesis [4,5]. In some $\mathrm{MM}$ cells, 17ß-estradiol $\left(\mathrm{E}_{2}\right)$ inhibits IL-6-mediated cell growth signaling, an effect overcomed by the specific antiestrogen (AE) ICI 182,780 (ICI, Faslodex $^{\circledR}$, Fulvestrant ${ }^{\circledR}$ ) [6]. It was also reported that 2methoxyestradiol (2ME2), a natural metabolite of $\mathrm{E}_{2}$ which does not bind to ERs is a potent antitumor and antiangiogenic agent in leukemic cells with the capacity to overcome drug resistance in MM cells [7]. The anti-proliferative effects of 2ME2 are mediated independently of ERs and its apoptotic capacity proceeds through production of reactive oxygen species [8] and Akt-dependent process [9].

In breast cancer cells, the mitogenic effects of $E_{2}$ are inhibited by AEs and the selective estrogen receptor modulator (SERM) tamoxifen is routinely used for the treatment of estrogen-dependent breast cancers [10]. The "pure" AE ICI is used in deep intramuscular injections in cases of tamoxifen resistance [11]. Besides their therapeutic role in breast cancer therapy, AEs down-regulate normal B-lymphopoiesis [12], significantly inhibit proliferation and/or induce apoptosis in several MM cell lines [13-16] as well as in MM patient cells [13]. Previous studies have established that both estrogen receptors $\alpha$ and $\beta$ isotypes (ER $\alpha$ and $E R \beta$, respectively) are expressed in some MM cells $[13,14,16,17]$. ERs are traditionally thought to function as transcription factors which target a number of genes [18]. Delineation of the molecular targets whereby AEs affect MM cell growth and survival might enhance our understanding of their action and might suggest novel therapies. Recently, we showed that in ER-positive MM cells, 4-hydroxy-tamoxifen (4-HT), the active metabolite of tamoxifen, induces cell death through the mitochondrial caspase-dependent apoptotic pathway $[15,16]$. However, the role of ERs in MM cells is still unclear since $\mathrm{E}_{2}$ has no impact on MM cell proliferation [13] and since both tamoxifen and 4-HT inhibit MM cell proliferation and induce program cell death at micromolar concentrations [13-16].

RU 58668 (RU), a poorly water-soluble "pure AE", acts powerfully in human breast cancer xenografts, but has a weak oral bioavailability [19-21]. Similarly to ICI, it induces quiescence as well as apoptosis in human breast cancer MCF-7 cells $[22,23]$. In the present work, we evaluated its activity on MM cell lines. At micromolar concentrations, we found that it decreases the proliferation of several MM cell lines, mainly by arresting cells at the G1-phase of the cell cycle. Previous investigations have shown that both tissue and cell distribution profiles of anticancer drugs can be controlled by their entrapment in submicronic colloidal systems $[24,25]$. Furthermore, we previously reported that drug delivery nanosystems improve the antitumoral activity of RU in breast cancer cells and tumors from MCF-7 cells xenografts [26].

RU incorporation in stealth liposomes was achieved leading to its controlled release. RU-loaded liposomes displayed both pro-apoptotic and antiangiogenic properties in vitro and had a strong antitumoral effect in xenografts at dosage at which the free RU had no effect. These results suggest that AE-loaded stealth liposomes could represent a therapeutic advantage for the treatment of MM.

\section{Materials and methods}

\subsection{Preparation and characteristics of stealth liposomes}

In a previous work [27], we described the preparation of different types of liposomes containing or not cholesterol at the following molar ratios: EPC/DSPE-PEG ${ }^{2000}$ (94:6) or EPC/CHOL/DSPE-PEG ${ }^{2000}$ (64:30:6). Their size $(105 \pm 31 \mathrm{~nm})$ are compatible with the capacity to extravagate towards a subcutaneous solid tumor following i.v. injection. The introduction of cholesterol known to rigidify the bi-layer, in EPC/DSPE-PEG ${ }^{2000}$ formulation slightly decreased the encapsulation rate (from $3.6 \mathrm{mM} \mathrm{RU} / 100 \mathrm{mM}$ lipids in EPC/DSPE-PEG ${ }^{2000}$ to $3.2 \mathrm{mM}$ RU/100 mM lipids in EPC/CHOL/DSPE-PEG ${ }^{2000}$ ).

\subsection{Biological kinetic activity of $R U$-trapped liposomes}

MELN cells are MCF-7 cells stably expressing the luciferase (LUC) reporter gene controlled by an estrogen responsive element linked to the minimal $\beta$-globin promoter. They were cultured in Dulbecco's modified Eagle's medium (Eurobio, Les Ulis, France) supplemented with L-glutamine $(2 \mathrm{mM})$, penicillin $(50 \mathrm{UI} / \mathrm{mL})$, streptomycin $(50 \mathrm{UI} / \mathrm{mL})$, $10 \%$ fetal calf serum (FCS). Prior AE treatment, cells were grown for 3 days in phenol-red free medium supplemented with charcoal-stripped FCS. Steroids, free or incorporated in liposomes, were placed in inserts (NUNC Anapore, membrane $0.02 \mu \mathrm{m}$, Nalge Nunc Inc., USA) disposed in culture dishes. Only free $\mathrm{RU}$ and $\mathrm{E}_{2}$ can cross the membranes. Inserts were removed from the dishes at 2, 6, 10 and $24 \mathrm{~h}$ and the incubations were further continued for $24 \mathrm{~h}$. Cells were then rinsed and lysed in $700 \mu \mathrm{L}$ of Tris/ $/ \mathrm{HPO}_{4} 25 \mathrm{mM}, \mathrm{MgCl}_{2}$ $10 \mathrm{mM}$, Triton X100 1\%, glycerol 15\%, EDTA $1 \mathrm{mM}, \mathrm{pH}$ 7.8 buffer on ice for $15 \mathrm{~min}$. Cell lysates were cleared by centrifugation $\left(10 \mathrm{~min}, 14,000 \mathrm{rpm}\right.$ at $\left.4{ }^{\circ} \mathrm{C}\right)$. LUC activities were measured in a luminometer (Lumat LB 9507, Berthold, France). For control, MELN cells were treated or not with $\mathrm{E}_{2}$ alone $(0.1 \mathrm{nM})$ in order to get $100 \%$ transcription, and with empty liposomes or RU ( $0.5 \mathrm{nM}$ free or liposomes incorporated).

\subsection{MM cell lines and normal B-cells}

MM cell lines LP-1, OPM-2, NCI-H929, RPMI 8226, U266 and Karpas 620 (described previously [28]) grew in RPMI 1640 medium (Eurobio) supplemented with 10\% decomplemented FCS. RU was obtained from P. Van de Velde (Roussel-Uclaf, Romainville, France) and ICI from Astra-Zeneca (Macclesfield, UK). For cell proliferation studies, cells were seeded in 6-well plates in triplicate $\left(2 \times 10^{5}\right.$ cells/well), in medium containing either vehicle or various RU concentrations. In some experiments, the specific P-glycoprotein (P-gp) inhibitor RU 49953 [29] (5 $\mu \mathrm{M})$ was added $1 \mathrm{~h} 30$ prior to RU. Tonsils were obtained from healthy donors with their informed consent in accordance 
with the Helsinki protocol. Mononuclear cells were isolated by centrifugation through Ficolle-Hypaque gradient. CD19+ (B-cells) subsets were isolated using specific antibodies coupled to magnetic microbeads (Miltenyi Biotec, Auburn, CA, USA). Purified B-cells were cultured in complete RPMI 1640 medium and were in vitro-activated $2 \mathrm{~h}$ before $\mathrm{AE}$ treatment by pokeweed mitogen (PWM, $5 \mu \mathrm{g} / \mathrm{mL}$ ). In some experiments, living cell content in culture exposed to drugs was estimated by Tripan blue exclusion as described in [16].

\subsection{Flow cytometry}

Cells $\left(1.3 \times 10^{5}\right.$ cells $\left./ \mathrm{mL}\right)$ were cultured in the presence or not of free RU, or of RU-loaded liposomes ( $1 \mu \mathrm{M}$ each), or with unloaded liposomes at the same lipid concentration. After treatment, cells were washed and fixed in PBS/ethanol (30/70). For cytofluorometric examination, cells $\left(10^{4}\right)$ were incubated for $30 \mathrm{~min}$ in PBS/Triton X100 0.2\%/EDTA $1 \mathrm{mM}$ /propidium iodide (PI, $50 \mu \mathrm{g} / \mathrm{mL}$ ) supplemented by RNase $(0.5 \mathrm{mg} / \mathrm{mL})$. Analyses were performed with a FACS Calibur (Becton Dickinson, Le Pont de Claix, France). Cell Quest software was used for data acquisition and analysis.

\subsection{Cellular uptake of fluorescent liposomes}

Fluorescent label $N$-(lissamine rhodamine-B sulfonyl)phosphatidylethanolamine-(N-Rh-PE, Avanti Polar, Coger, Paris, France) $(0.5 \%)$ containing liposomes (total lipids $150 \mu \mathrm{M})$ were added to RPMI 8226 cells. After overnight incubation at either 4 or $37^{\circ} \mathrm{C}$, cells were rinsed five times with ice-cold PBS and visualized using a Nikon TE-2000S fluorescent microscope (Nikon, Champigny/Marne, France) coupled to a Nikon Coolpix digital camera. Lucia Image was used for image processing. In other experiments, the cellular localization of the fluorescent N-Rh-PE liposomes was carried out using a LSM510 Zeiss laser scanning confocal microscope equipped with a C-Apochromat $40 \times / 1.2 \mathrm{~W}$, and a water immersion objective. Observations were based on merged and unmerged (Nomarski) series of optical sections of $0.5 \mu \mathrm{m}$ analyzed at $543 \mathrm{~nm}$.

\subsection{Western blotting}

Cell lysates were obtained by resuspending MM cells in the following buffer: $1 \%$ NP40, $50 \mathrm{mM}$ Tris, $10 \%$ glycerol, $150 \mathrm{mM} \mathrm{NaCl}, 1 \mathrm{mM}$ EDTA, pH 7.5, plus protease inhibitors (Roche Diagnostics, Meylan, France). For obtaining total cell extracts (TCEs), cells were resuspended in the same buffer containing $0.4 \mathrm{M} \mathrm{NaCl}$. Centrifuged cells or tumor homogenates were boiled for $10 \mathrm{~min}$ in Laemmli sample buffer, and centrifuged $\left(205,000 \times g, 1 \mathrm{~h}, 4^{\circ} \mathrm{C}\right)$. Proteins were separated by electrophoresis on SDS/PAGE, blotted onto cellulose membranes (Hybond-C super, Amersham Biosciences, Les Ulis, France) and incubated with various antibodies (Abs) as described previously [16]. Abs used were: anti-Mcl-1 (sc-819), anti-Bcl- $\mathrm{X}_{\mathrm{S} / \mathrm{L}}$ (sc-634), anti-
Bcl-2 (sc-783), anti-Bax (sc-493), anti- $\beta$-tubulin (sc-9104), anti-cytochrome $c$ (sc-13560), anti caspase-8 (sc-7890), anti caspase-3 (sc-7148), anti-PARP (sc-8007) from Santa Cruz Biotechnologies (Santa Cruz, CA, USA), and anti-Bid (no 2002) from Cell Signaling Technology (Beverly, MA, USA).

\subsection{Xenografts}

Female NMRI nude mice (7-8 week-old, Janvier, France) were exposed $5 \mathrm{~min}$ to $\gamma$ irradiation from a ${ }^{137} \mathrm{Cs}$ irradiator at a dose rate of $50 \mathrm{cGy} / \mathrm{min}$. The next day, RPMI 8226 cells $\left(10^{7} / 100 \mu \mathrm{L}\right)$ were s.c. inoculated. Tumors were let to grow during 6-8 weeks until to reach $300-500 \mathrm{~mm}^{3}$ then mice were treated in conditions similar to those described previously [27]. Free RU ( $12 \mathrm{mg} / \mathrm{kg} /$ week) dissolved in $0.9 \% \mathrm{NaCl}$ containing 5\% EtOH, RU-loaded liposomes (12 mg RU/kg/week) and unloaded liposomes at the same lipid concentration were i.v. injected once a week. Tumors were excised and bisected: half the tumor was immediately fixed in Finefix (Milestone s.r.l., Sorisole, Italy) for TUNEL or immunohistochemistry and the other half was homogenized in Hepes $50 \mathrm{mM}, \mathrm{NaCl} 0.4 \mathrm{M}$, EDTA $1 \mathrm{mM}$, glycerol $10 \%$, DTT $1 \mathrm{mM}, \mathrm{pH} 7.8$ buffer containing protease inhibitors in a glass/glass homogenizer. During the experiments, mice were maintained in accordance with the principles of the Declaration of Helsinki and in respect of the French legislation on animal welfare.

\subsection{Terminal deoxynucleotidyl transferase-mediated dUTP nick-end-labeling (TUNEL)}

Paraffin sections $(4 \mu \mathrm{m}$-thick) from fixed tumors were prepared. After deparaffinization and xylene treatment, sections were rehydrated, TUNEL was performed using the In Situ Cell Death Detection Kit, AP (Roche Diagnostics, $\mathrm{GmbH}$, Mannheim, Germany) according to the manufacturer's instructions. The sections received microwave pretreatment in citric acid buffer for antigen retrieval. Samples were submitted to image analysis. TUNEL-positive cells, displaying compaction or segregation of the nuclear chromatin or breaking of the nucleus into discrete fragments, were counted.

\subsection{Immunohistochemistry}

Paraffin sections were xylene treated then rehydrated. Following antigen retrieval, immunohistochemistry of murine endothelial cells (anti-mouse CD34 ${ }^{+} \mathrm{Ab}$ clone MEC14.7, HyCult biotechnology b.v., The Netherlands) was performed. Sections were incubated with blocking serum (Biogenex buffer 1:10, San Ramon, CA, USA) for $10 \mathrm{~min}$, followed by incubation with anti-CD34 Ab diluted 1:20 in blocking serum during $1 \mathrm{~h}$. Slides were then incubated with a rabbit anti-rat Ab (Dako, Denmark) diluted 1:200 in blocking serum. The following step consisted in a rabbit PowerVision kit (ImmunoVision Technologies, CA) 20 min and DAB $10 \mathrm{~min}$. Slides were counterstained with Mayer's hematoxilin 
and mounted (Pertex). Anti-CD138 Ab (Clone MI 15, Dako, Denmark) was used at 1:50 dilution and visualized with Histo Mouse Max kit (Zymed, CA) for MM cell characterization in tumors. Analyses were then performed as for CD34.

\subsection{VEGF quantification}

Human VEGF was measured with the Quantikine ${ }^{\circledR}$ Kit (R\&D systems, GmbH, Germany). Briefly, cells $\left(5 \times 10^{6}\right)$ were exposed or not to free RU or RU-liposomes $(1 \mu \mathrm{M})$ or to empty liposomes for 24 or $48 \mathrm{~h}$. Cells were removed by centrifugation and the supernatant was further treated according to the manufacturer's instructions.

\subsection{Statistical analysis}

The Student $t$-test was used to determine the significance of differences between two experimental groups. Mean of

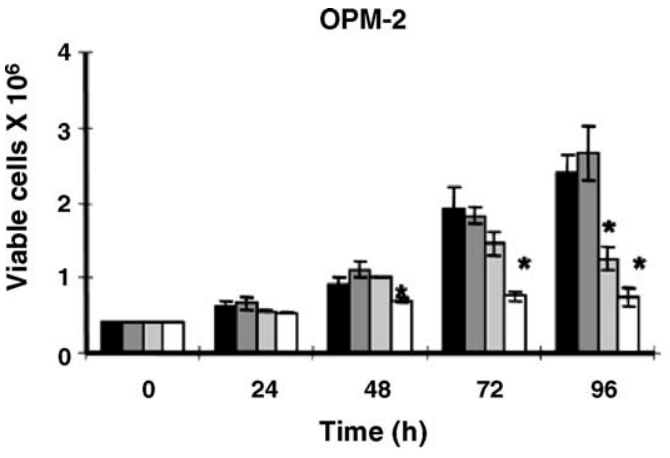

RPMI 8226
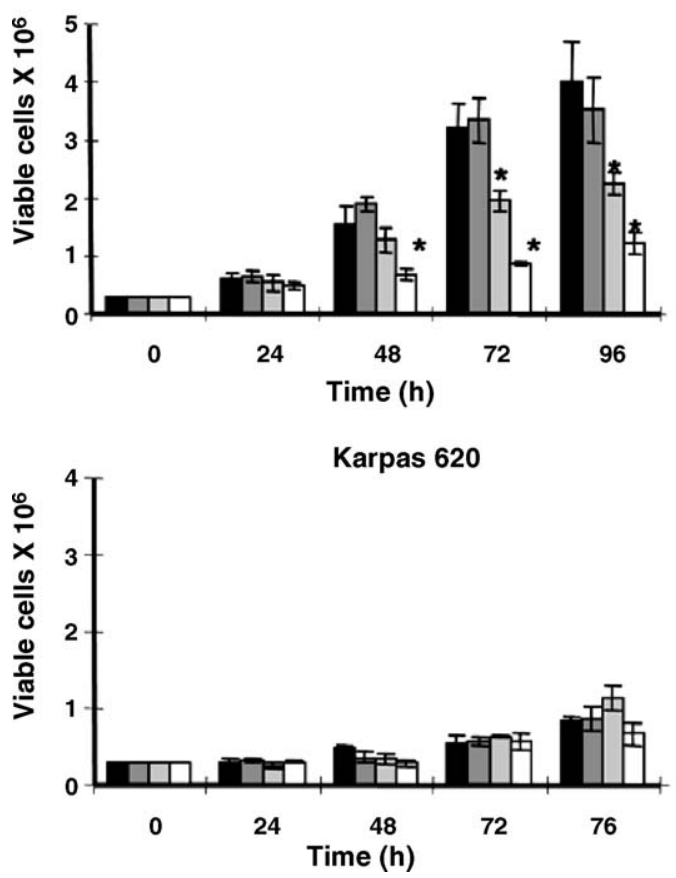

triplicates were analyzed by a two-sided test and $P<0.05$ was considered significant. Repeated measures ANOVA test was used for comparisons of tumor proliferation groups.

\section{Results}

\section{1. $R U$ impairs the proliferation of MM cells}

We previously reported that 4-HT treatment inhibited in a dose- and time-dependent fashion the proliferation of several MM cell lines $[15,16]$. We now extended these studies to two other "pure" AEs: RU and ICI. Fig. 1 revealed a RU-sensitive, time- and dose-dependent proliferation inhibition of OPM-2, NCI-H929, RPMI 8226, LP-1 and U266 cell lines. Among the cell lines studied, OPM-2 and RPMI 8226 were the most sensitive since as soon as $48 \mathrm{~h}$ post-treatment, $10 \mu \mathrm{M}$ RU decreased significantly their proliferation. In NCI-

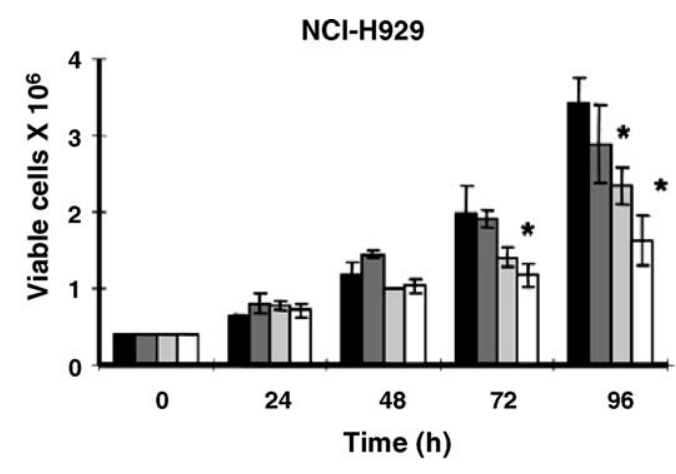

LP-1

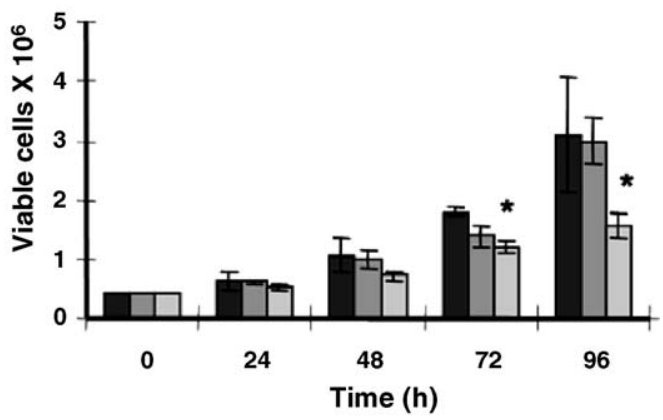

U266

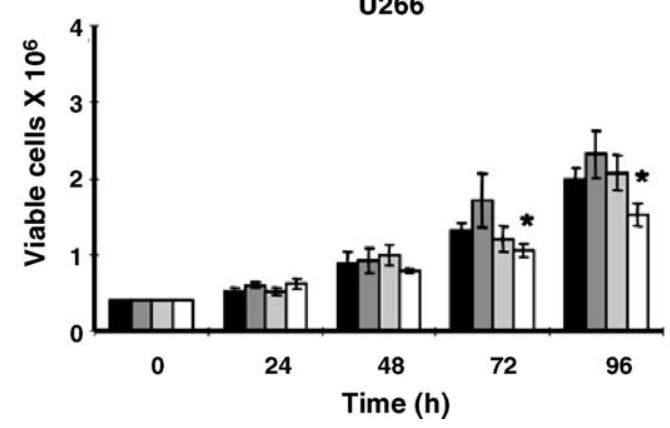

Fig. 1. Proliferation of RU-treated MM cells. Exponentially growing MM cells were seeded and treated with $1(\square), 5(\square)$, or $10 \mu \mathrm{M}$ RU ( $\square$ ) or with vehicle $(\mathrm{EtOH})(\mathbf{\square})$. Cells were counted every day during the 4-day period of culture. The number of viable cells excluding trypan blue is plotted vs. time. Experiments were performed in triplicate, values are means \pm S.D. ${ }^{*} P<0.05$. 
H929, LP-1 and U266, such a RU concentration displayed an inhibitory effect later $(72 \mathrm{~h})$. Similar results were observed using ICI (data not shown). The proliferation rate of Karpas 620 cells was very low avoiding precise assessment of sensitivity towards RU. Nevertheless, as for 4-HT inhibition of proliferation in several $\mathrm{MM}$ cells occurring at high $\mathrm{AE}$ concentration $(>5 \mu \mathrm{M})$ is puzzling and severely questioned the involvement or nor of ER.

\subsection{Release properties of $R U$-loaded liposomes}

Since RU effects were observed at micromolar concentrations, in order to perform further in vivo experiments, we incorporated it in liposomes known to get high incorporation capacity. Several formulations with various lipid composition and containing or not CHOL were realized [27]. The total concentration of $\mathrm{RU}$ in all formulations was higher than $1 \mathrm{mM}$. It is known that the AE-mediated inhibitory capacity of $\mathrm{E}_{2}$-induced LUC expression is dose- and time-dependent. We then measured the luciferase activity of MELN cells exposed or not to free and encapsulated RU at various concentrations. Fig. 2 shows that $50 \%$ inhibition of $\mathrm{E}_{2}$ induced luciferase activity occurred quite similarly with both free and RU from EPC/DSPE-PEG ${ }^{2000}$ liposomes (69 and $89 \mathrm{~min}$, respectively). In case of CHOL-containing formulation, 50\% inhibition was reached at $296 \mathrm{~min}$, suggesting that RU released slowly from EPC/CHOL/DSPE-PEG ${ }^{2000}$ liposomes. The later formulation was then chosen in further experiments.

\subsection{RU-loaded liposomes induce apoptosis in MM cells but not in normal B-cells}

In contrast to other MM cells [27], RPMI 8226 cells were extremely sensitive since a dose-dependent apoptosis

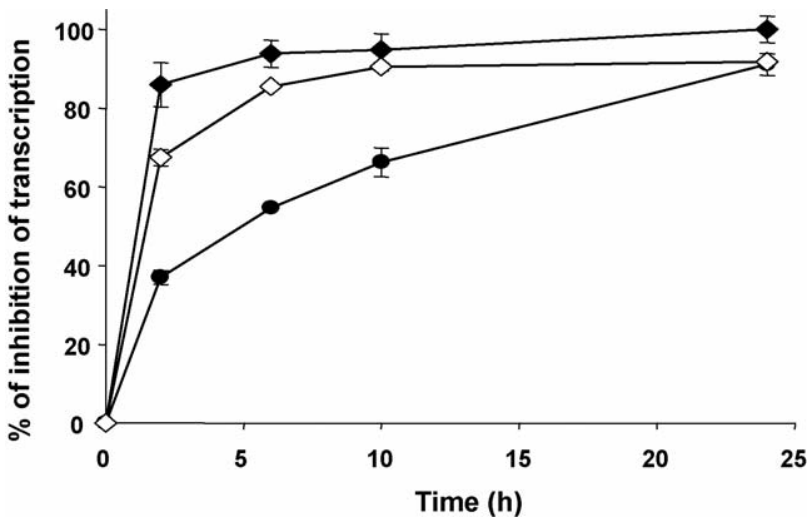

Fig. 2. Time-dependent release of RU from liposomes. Influence of the lipid composition upon RU release from liposomes. MELN cells were exposed to inserts containing or not free RU or RU-containing liposomes in the presence of $0.1 \mathrm{nM} \mathrm{E}_{2}$ for various times. After each incubation time, the inserts containing RU-liposomes were removed and cells were further cultured for $24 \mathrm{~h}$ then LUC activities were measured. The figure summarizes the data obtained with free RU $(\diamond)$ at $0.5 \mathrm{nM}$, RU-loaded EPC/DSPE-PEG ${ }^{2000}$ liposomes $(\diamond)$ at $0.5 \mathrm{nM}$ and RU-loaded EPC/CHOL/DSPE-PEG ${ }^{2000}$ liposomes (O) at $0.5 \mathrm{nM}$. Means of triplicates \pm S.D. are indicated but not always visible on the curves when too small to be distinguished from the mean. Empty liposomes had no effect on $\mathrm{E}_{2}$-induced luciferase activity in MELN cells (not shown).

induction was detected as soon as $48 \mathrm{~h}$ at $5 \mu \mathrm{M}$ RU simultaneously with an arrest in the G1-phase. Importantly, at 1 and $10 \mu \mathrm{M}$, RU has no effect neither on cell cycle nor on apoptosis in normal B-cells (Table 1). On the contrary, RU-loaded liposomes triggered apoptosis in all tested cells [27] and in RPMI 8226 cells (this work). Indeed, a high proportion of cells in the sub-G1 fraction increased timeand dose-dependently. Empty liposomes were devoid of any effect in RPMI 8226 as well as in other MM cells and in B-cells (data not shown). Thus, the encapsulation of RU in

Table 1

Cell cycle distribution of RPMI 8226 MM and B-cells treated with RU

\begin{tabular}{|c|c|c|c|c|c|}
\hline Cell & Treatment & G0/G1 & $S$ & $\mathrm{G} 2 / \mathrm{M}$ & Sub-G1 \\
\hline \multirow{5}{*}{ RPMI 8226} & $\mathrm{EtOH}$ & 33.3 & 53.2 & 13.4 & 2.6 \\
\hline & RU $1 \mu \mathrm{M}$ & 34.1 & 46.9 & 18.9 & 4.5 \\
\hline & RU $5 \mu \mathrm{M}$ & 46.4 & 42.4 & 11.2 & 26.5 \\
\hline & RU $10 \mu \mathrm{M}$ & 31.2 & 59.5 & 9.3 & 38.2 \\
\hline & RU-loaded lip. $1 \mu \mathrm{M}$ & $39.2(48.6)$ & $47.3(34.7)$ & $13.5(16.7)$ & $46.0(38.0)$ \\
\hline \multirow{5}{*}{ B-cells (CD 19+) } & $\mathrm{EtOH}$ & 82.2 & 4.5 & 0.8 & 7.5 \\
\hline & RU $1 \mu \mathrm{M}$ & 82.2 & 6.1 & 0.9 & 7.1 \\
\hline & RU $10 \mu \mathrm{M}$ & 78.3 & 6.4 & 1.3 & 9.0 \\
\hline & Liposomes & 81.3 & 4.8 & 1.3 & 7.7 \\
\hline & RU-loaded lip. $1 \mu \mathrm{M}$ & 80.5 & 6.0 & 1.5 & 7.4 \\
\hline
\end{tabular}

MM cells were treated for 48 or $72 \mathrm{~h}$ (percentages in parentheses) with vehicle (EtOH) or various concentrations of free RU (1-10 $\mu M$ ), or with RU-loaded liposomes (RU-loaded lip.) at $1 \mu \mathrm{M}$ RU. Cell cycle analyses were performed after PI staining of EtOH-permeabilized cells. The percentages of cells in the different phases of the cell cycle as well as cells exhibiting a sub-G1 DNA content are indicated. Representative experiments are shown in all cell lines, experiments have been repeated 2-4 times for each free RU concentration $(1-10 \mu \mathrm{M})$. Normal human B-lymphocytes isolated from tonsils were purified on the basis of CD19 expression. B-cells were cultured in complete medium with $5 \mu \mathrm{g} / \mathrm{ml}$ PWM $12 \mathrm{~h}$, then treated with vehicle (EtOH), $1-10 \mu M$ free RU, unloaded liposomes or RU-loaded liposomes ( $1 \mu \mathrm{M} \mathrm{RU})$ for $48 \mathrm{~h}$ then analyzed with the cytofluorometer after PI staining. Mononuclear bone marrow cells were freshly isolated from a MM patient, CD138+ cells were purified, incubated with vehicle (EtOH), 1-10 $\mu$ M RU, empty liposomes or RU-loaded liposomes (1 $\mu$ M RU) for $48 \mathrm{~h}$. Cells were PI-stained and analyzed with the cytofluorometer. 
liposomes provokes apoptosis in all tested MM cell lines including those in which free RU had no apoptotic effect.

\subsection{RU-loaded liposomes induce apoptosis in xenografts}

Nude mice injected with RPMI 8226 cells developed solid tumors localized at the inoculation site. An example of the tumor aspect at 5 week treatment is given (Fig. 3A). Histologically, a dense malignant population of cells of hematopoietic origin was observed in the tumors, displaying dark granular cytoplasm characteristic of malignant plasma cells (not shown). In good correlation with the initial characteristics of the parental cells, tumor cells were CD38+, CD138+ (Fig. 3A), CD56-, and smк-/ $\lambda-$. In order to evaluate the in vivo anti-proliferative activity of RU, free $\mathrm{RU}, \mathrm{RU}$-loaded liposomes or empty liposomes were i.v. injected once a week $(12 \mathrm{mg} / \mathrm{kg})$. Such a RU dosage was not toxic in vivo as previously observed [26]. Previous experiments [27] indicated that the mean volume of tumors at 8 weeks treatment increased 18-fold in the control group, similarly to mice treated with free RU and with unloaded stealth liposomes. In contrast, the mean size of tumors from mice treated with RUloaded stealth liposomes increased only three times. Density of CD138+ cells decreased in tumors from mice injected with RU-liposomes, in agreement with the reduction of the tumor size and was not affected in tumors from unloaded liposomestreated mice (Fig. 3A). On histological stained sections, we observed, within tumors treated with RU-liposomes, a destruction of individual cells within a preserved environment suggestive of an increased apoptotic activity. This was confirmed by TUNEL experiments. Remarkably, a strong
(A) Tumor aspect
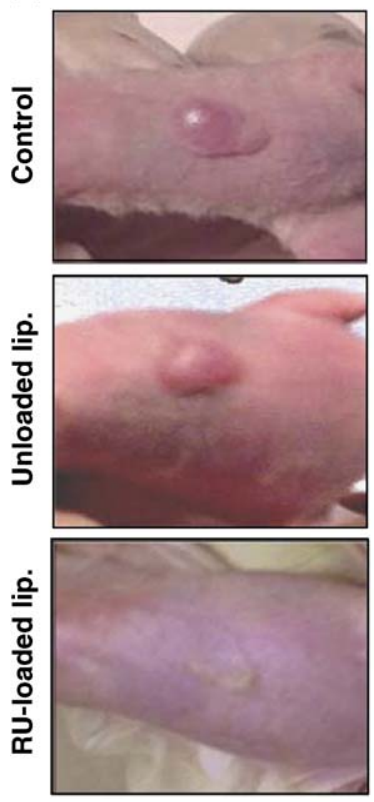

CD138
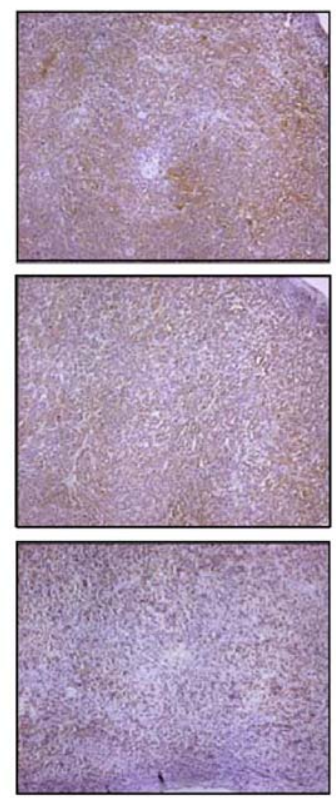

TUNEL
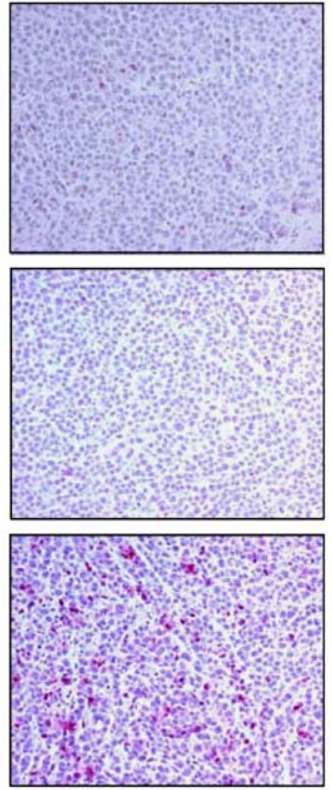

CD34
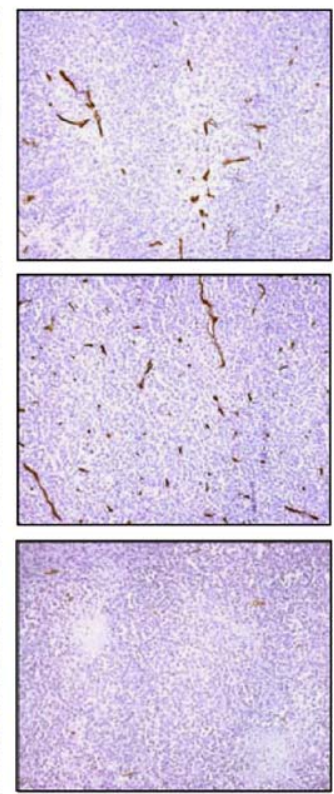

(B)

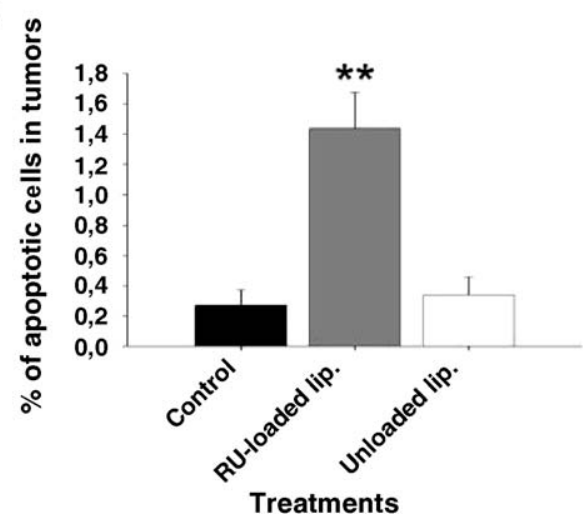

Fig. 3. Effects of RU-loaded liposomes on RPMI 8226 xenografts. (A) Tumors from mice injected or not (control) with empty liposomes or with RU-charged liposomes were removed after 5 weeks of treatment and fixed for further immunostaining. Examples of representative treated mouse from each group are shown (left column). CD138 staining at 100 $\times$ original magnification, TUNEL-staining at $200 \times$ original magnification and anti-CD34-staining at $100 \times$ original magnification are presented for each group of mice. Images are representative of five different similarly treated tumors. (B) The increase of apoptosis was quantified from TUNEL experiments performed in panel A. Histograms are the mean ( \pm S.E.M.) of counts performed on five fields $(200 \times)$ of apoptotic cells in a population of around 900 cells per image from five different tumors. ${ }^{* *} P<0.01$. 
increase of apoptotic nuclei labeling was noticed in samples treated with RU-liposomes for already 5 weeks, significantly different from the control groups (Fig. 3A and B).

\subsection{RU-liposomes reduce the tumor vasculature in vivo and VEGF secretion in vitro}

Blood vessel immunohistological staining on tumor sections from mice treated or not with RU-liposomes was performed with the anti-CD34 Ab. Necrotic areas were excluded from the microscopical examinations, since microvasculature features may be artifactual in these regions. Concomitantly with an increase of apoptotic cells in tumors, a strong diminution of the tumor capillaries labeling was observed after injection of RU-liposomes for 5 weeks (Fig. 3A). Meanwhile, no differences were seen in control tumors as well as in tumors from mice injected with empty liposomes. Since VEGF is the major stimulator of tumor vessel growth in MM [30], we further checked for the influence of RU on the expression level of VEGF in RPMI 8226 cells. As shown in Fig. 4, a decrease of VEGF secretion was observed at $24 \mathrm{~h}$ when cells were exposed to free RU but not in cells treated with RU-loaded or unloaded liposomes. On the contrary, at $48 \mathrm{~h}$, a $25 \%$ inhibition was obtained in cells treated with free RU and a 50\% with RU-loaded liposomes. This is in agreement with a slow RU-release from the liposomes and a better RU activity following its liposomal delivery. Thus, one of the mechanism by which RU-liposomes inhibit tumor progression could be due to the ability of RU to inhibit VEGF synthesis.

\section{6. $R U$-liposomes endocytosis may counteract $R U$ extrusion from MM cells}

$\mathrm{N}-\mathrm{Rh}$-PE-labeled liposomes were incubated with RPMI 8226 cells and analyzed by fluorescent microscopy. Fig. 5A

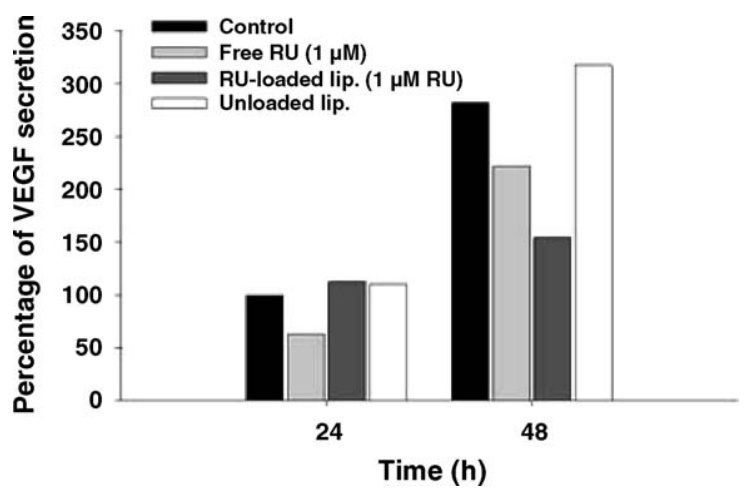

Fig. 4. In vitro decrease of VEGF in RPMI 8226 cells following RU 58668 treatment. RPMI 8226 cells were exposed or not (control) to free RU $(10 \mu \mathrm{M})$, or to empty liposomes or to RU-loaded liposomes (1 $\mu \mathrm{M} \mathrm{RU})$ for 24 and $48 \mathrm{~h}$. After removal of cells, living cells were quantified with a MTT test and the culture media were analyzed for VEGF secretion measurement. Results are expressed as percentage of secreted VEGF normalized to the living cell number determined by Tripan blue exclusion with $100 \%$ affected to the control at $24 \mathrm{~h}$.
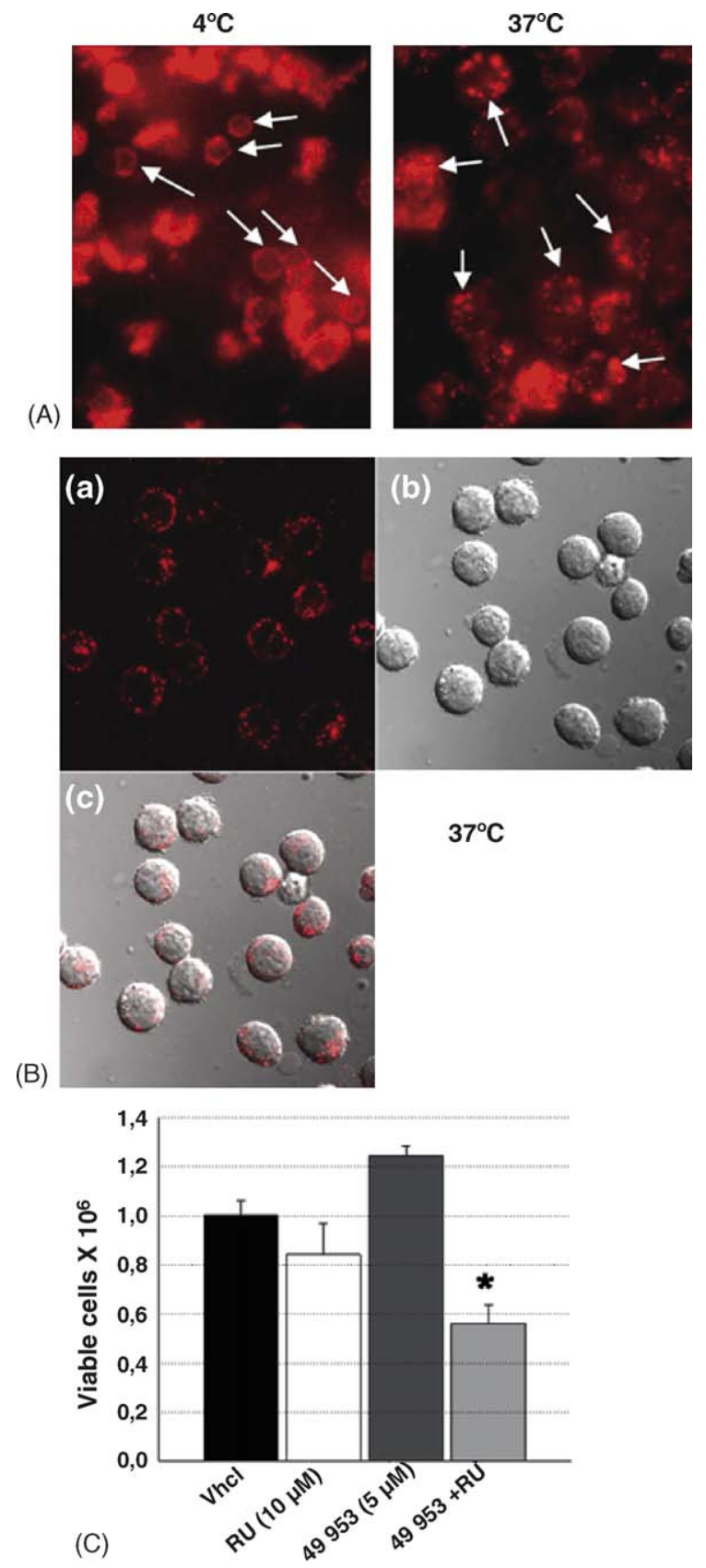

Fig. 5. Consequence of endocytosis inhibition and of selective membrane efflux blockade in RPMI 8226 cells exposed to liposomes and/or to RU. (A) RPMI 8226 cells were incubated overnight with rhodamine-labeled liposomes ( $150 \mu \mathrm{M}$ final lipids) at 4 or $37^{\circ} \mathrm{C}$ and analyzed by fluorescence microscopy. A substantial fluorescent signal was located at the cell surface when endocytosis was blocked (left panel; $4^{\circ} \mathrm{C}$ ). At $37^{\circ} \mathrm{C}$, fluorescence appeared as a heterogeneous population of red spots (right panel) within the cell (depicted by white arrows). (B) N-Rh-PE liposomes were introduced in the culture medium of RPMI 8226 cells growing at $37^{\circ} \mathrm{C}$ and cells were analyzed $18 \mathrm{~h}$ later by laser confocal microscopy. The fluorescence is shown in (a) and the differential interference contrast (Nomarski) is shown in (b). The superimposition of the dye and the cells is shown in (c) revealing both a strong perinuclear labeling in all planes of the cells and some labeling inside the cells. (C) RPMI 8226 cells were treated or not (Vhcl) for $90 \mathrm{~min}$ with $5 \mu \mathrm{M}$ RU 49953 prior to or not incubation with RU $10 \mu \mathrm{M}$ during $24 \mathrm{~h}(n=3)$. Cell viability was then evaluated by trypan blue exclusion. One hundred percent viability was affected to control (Vhcl) at $24 \mathrm{~h} .{ }^{*} P<0.05$. 
suggests that liposome uptake by the cells occurred following incubation only at $37^{\circ} \mathrm{C}$. No intra-cellular labeling was depicted at $4{ }^{\circ} \mathrm{C}$, a temperature known to inhibit endocytosis [31,32]. Since it was previously shown that rhodamine is a substrate for P-glycoproteins (P-gps) [33], we further checked for the intra-cellular uptake of rhodamine-labeled liposomes by laser scanning confocal microscopy and measured the influence of a P-gp inhibitor upon the AE-induced

(A) RPMI 8226 cells

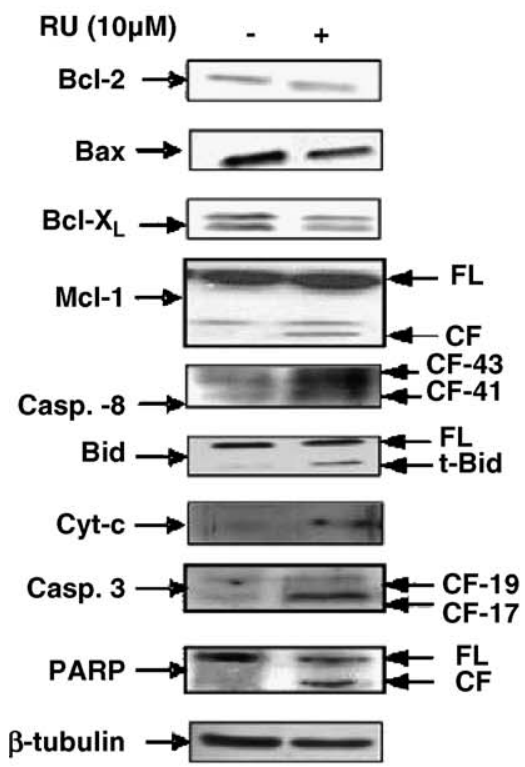

inhibition of MM cell viability. Fig. 5B (panel c) depicted a strong fluorescence in the periphery as well as inside RPMI 8226 cells in all the planes of the cells. This experiment suggests that rhodamine accumulated inside the cells through likely endocytosis of N-Rh-PE-labeled liposomes because in case of free rhodamine released from the formulation, the dye cannot enter the cells and would have been extruded by the P-gps.

(B) RPMI 8226 tumors

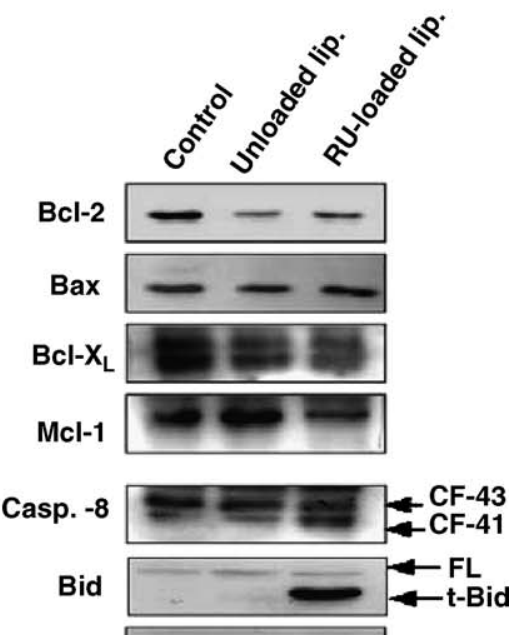

$\beta$-tubulin

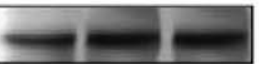

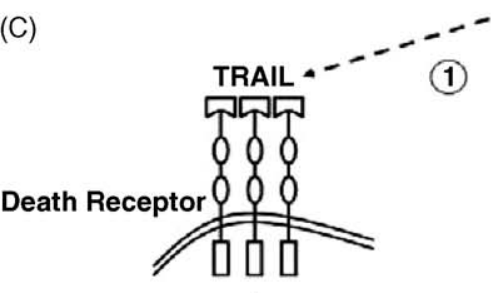

RU

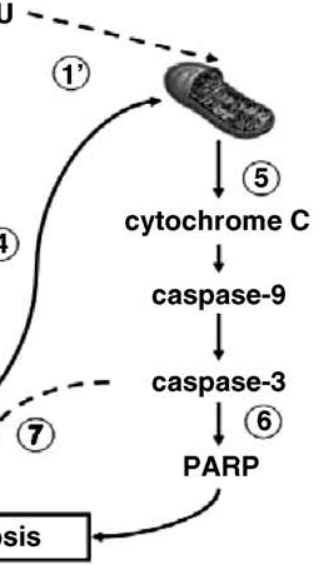

Fig. 6. Analysis of apoptotis regulators in RPMI 8226 cells and in xenografts. (A) Total cell extracts (TCE, $30 \mu \mathrm{g}$ proteins) from RPMI 8226 cells vehicle-treated $(-)$ or stimulated with $10 \mu \mathrm{M} \mathrm{RU}(+)$ for $48 \mathrm{~h}$ were subjected to immunoblotting with the corresponding antibodies. $\beta$-Tubulin was shown as marker of protein loading. (B) TCEs (100 $\mu \mathrm{g}$ proteins) from RPMI 8226 xenografts, injected or not with either unloaded liposomes (Unloaded lip.) or RU-loaded liposomes (RU-loaded lip.), harvested at 5 week treatment were prepared and immunoblotted. Tumor extracts from five animals from the same group were mixed. (C) Schematic representation of the caspase cascade activated by RU. RU could mediate either the activation of caspase- 8 through activation of TRAIL-DR extrinsic death pathway (1) and/or mitochondrial activation (1') allowing the release of cytochrome $c(5)$, the activation of caspase-9, the activation of caspase-3, the proteolysis of PARP (6) leading to the completion of apoptosis. As a consequence of activation of caspase-8 (2), Bid is cleaved (3) and t-Bid amplifies apoptosis acting on the release of pro-apoptotic molecules from mitochondria (4). Alternatively caspase- 8 could be directly the target of caspase-3 (7). 
Like many steroids, RU could be exported from cancer cells displaying a multidrug resistance (MDR) phenotype due to the activity of P-gps [34,35]. RU 49953 is a specific P-gp inhibitor, stronger than verapamil itself and capable of reverting MDR [29]; we further analyzed its effects upon RUmediated inhibition of MM cell viability. RU 49953 had no cytotoxic effects compared to vehicle-treated cells (Fig. 5C). Compared to RU-treated RPMI 8226 cells, significantly less cells survived when they were exposed to RU in the presence of RU 49953. Similar results were obtained with 4-HT (data not shown), suggesting that blocking P-gp could enhance AE capture. Altogether, data from Fig. 5A-C suggest that uptake of RU in MM cells could be modulated by P-gps and that its incorporation in liposomes facilitates its intra-cellular accumulation.

\section{7. $R U$ mediates apoptosis through the mitochondrial cell death pathway}

In order to decipher the mechanisms involved in RUmediated apoptosis, we investigated the expression of Bcl-2 family members, the caspases status and the level of apoptosis modulators in RPMI 8226 cells and xenografts treated in vitro and in vivo with RU, respectively. Exposure to RU had no significant effects on the levels of Bcl-2, Bcl-X, Bax (Fig. 6A and B). On the contrary, Mcl-1 (FL, 37 kDa) was cleaved in a product of $25-27 \mathrm{kDa}(\mathrm{CF}$, Fig. $6 \mathrm{~A})$ in vitro and was down-regulated in vivo (Fig. 6B) Treatment with RU initiates a spectrum of events characteristics of mitochondrial apoptosis: the release of cytochrome $c$ in cytosolic extracts, the processing of caspase- 3 proform $(36 \mathrm{kDa})$ into two mature cleaved forms (19 and $17 \mathrm{kDa}, \mathrm{CF}-19$ and CF-17), and finally the proteolysis of caspase substrate, poly(ADPribose)polymerase or PARP (the $110 \mathrm{kDa}$ long form FL giving a $85 \mathrm{kDa}$ proteolytic fragment $\mathrm{CF}$ ). Caspase- 8 was also activated following RU-treatment. The proform of caspase- 8 gave two cleaved products (CF-43 and -41 of 43 and $41 \mathrm{kDa}$ ), and its substrate $\mathrm{Bid}$, a pro-apoptotic $\mathrm{BH} 3$ domain-containing member of the Bcl-2 family, is also cleaved to give truncated Bid (t-Bid). Activation of caspases occurred both in RPMI 8226 cells and xenografts leading us to conclude that the mitochondrial death pathway is triggered by RU.

\section{Discussion}

The main goal of our work was the development of a drug delivery system for the administration of an $\mathrm{AE}$ able to induce apoptosis in MM tumor cells. The pegylated liposomes we developed resist the opsonization process and the macrophage capture once injected in the blood stream. Indeed, surface-grafted PEG (polyethylene glycol) hydrophilic chains of many colloidal injectable systems strongly prolong the half-lives of formulations [36,37]. In MM cell lines, only high RU concentrations lead to a significant slowdown of cell proliferation and induction of apopto- sis. With regard to the molecular target of AE in MM cells, due to the high concentrations needed, no evidence emerged for a classical ER-mediated mechanism by which not only RU and Faslodex (this work) and other AE like tamoxifen (our previous work $[15,16]$ and that of others $[13,14]$ ) could induce cell cycle arrest and/or apoptosis. It is still unclear why so high $\mathrm{AE}$ amounts are needed in MM cells to get such effects. Part of an explanation could imply a membrane extrusion P-gpmediated mechanism, more active in MM cells than in breast cancer cells. It could be also possible that ER ligands target a species of AE-binding protein, leading to ER-unreliable effects. Indeed, ER was shown to localize at the membrane of breast cancer cells and a small amount of ER exists in some cells as a functional non-traditional G-protein coupled receptor at the plasma membrane $[38,39]$. Whether such receptors mediate the effects of AEs in MM cells remains to be established and is the matter of current investigations. However, part of their activity is mediated through ER $\alpha$ and $E R \beta$ since their transient transfection in ER-null and AE-insensitive MM cells restore the capacity of 4-HT to inhibit cell proliferation [16]. In addition, both ER isotypes are functional in the RPMI 8226 cells as demonstrated by the $\mathrm{E}_{2}$-increased luciferase activity measured after transfection of an ERE-tkLUC construct (our unpublished work).

The liposomes we synthesized contained at least five times more RU than that contained in stealth nanospheres of PEGpoly-(DL lactic acid) (PEG-PLA) we formulated previously [40]. RU-containing liposomes composed of EPC/DSPE$\mathrm{PEG}^{2000}$ (94:6) were not appropriate for in vivo use since they released RU rapidly. The leakage of RU on one hand, and the high encapsulation rate on the other hand were quite similar to those obtained with other amphiphilic drug loaded liposomes [41]. A significant release reduction was obtained by including cholesterol within the bi-layer. We have reported earlier that RU incorporated in nanoparticles made of PEGPLA enhance the antitumor activity in a MCF-7 human breast cancer cell xenograft model by accumulation of the drug formulation in the tumor [26]. Such an accumulation is thought to be the consequence of several factors: the long-circulating time of the colloidal systems and the non-linear vasculature of the tumor tissues which consequently induce a high local drug-containing liposome concentration at the tumor level, altering the drug biodistribution and increasing its therapeutic index $[37,41]$. We found that cholesterol-containing liposomes were good candidates to do so. We further evaluated in vivo the capacity of these RU-liposomes to affect tumor growth in RPMI 8226 xenografts. Although not really reproducing the exact human pathology, this commonly used model $[7,42,43]$ preserves neo-angiogenesis characteristics necessary for the development of the disease. In such xenografts, the antitumor activity of RU-liposomes reveals the potent efficiency of the combined association between an $\mathrm{AE}$ and its disease-adapted drug delivery. TUNEL experiments confirmed the permissiveness of RU-mediated apoptosis when packaged in liposomes while unloaded liposomes were devoid of any activity. This capacity was also observed 
in vitro by the increasing number of cells in sub-G1 after RUliposome treatment (Table 1). Previous reports showed a comparable enhancing effect of other pegylated colloidal systems. For example, incorporation of anthracyclines in liposomes improve both the cytotoxicity and the drug accumulation in murine solid tumor models [44-46] as well as in MM [47].

Analysis of molecular regulators and effectors of apoptosis showed that the same pathways are recruited in vitro and in vivo (Fig. 6A and B). From the present data, RU seems to trigger apoptosis through the intrinsic mitochondrial death pathway. Indeed, under RU-treatment, cytochrome $c$ is released from mitochondria, and activates the executioner caspase- 3 which cleaves its cellular target poly (ADP-ribose) polymerase-1 (PARP). Whether caspase-9 is involved is likely but remains to be demonstrated. We also found that RU-treatment resulted in the activation of caspase- 8 and in turn in Bid cleavage (Fig. 6A and B). Truncated Bid (t-Bid) can then enhance the release of mitochondrial proteins establishing a cross-talk between extrinsic and intrinsic pathways. Indeed, caspase- 8 is the apical caspase of the extrinsic death receptor pathway [48]. Caspase-8 traditionally is associated with Fas receptor-induced apoptosis. We have previously reported that Fas expression was not modified after 4-HT treatment in MM cells [16] and in both human MCF-7 breast cancer cells and RPMI 8226 MM cells, we did not get activation of Fas through RU (our unpublished work). As a consequence, how RU-treatment engages the death receptor pathway remains open. TRAIL (tumor necrosis factor (TNF)related apoptosis-inducing ligand) induces apoptosis in MM cells through engagement of death receptors (DR4 and DR5) [49]. TRAIL/DR pathway could be a direct or indirect target of RU. Alternatively, caspase- 8 and its substrate Bid could be activated in a death receptor-independent manner from a caspase-3-mediated activation initiated by cytochrome $c$ release (Fig. 6C). Members of the Bcl-2 family: Bcl-2, Bcl-X, Bax (Fig. 6A and B) are modified only slightly following RUtreatment. But importantly, Mcl-1, recognized as the major survival protein in MM cells [50,51], is both cleaved in vitro (Fig. 6A) likely by a caspase activity and down-regulated in vivo (Fig. 6B). Interestingly, it has been shown recently in Jurkat leukemic cells that in TRAIL-induced apoptosis, caspase-3-cleaved Mcl-1 became pro-apoptotic and physically interacted with t-Bid to enhance mitochondrial apoptosis [52]. The proposed model in Fig. 6C differs from the one proposed by Chauhan et al. [7] showing that 2ME2 activates caspase- 3 through a mitochondrial pathway leading to release of Smac/DIABLO. Indeed, we have not found any effect of RU on the Smac/DIABLO release (not shown).

Interestingly, the pro-apoptotic activity of RU-liposomes superimposed to the capacity of RU to decrease VEGF secretion in vitro (Fig. 4) and to diminish the capillary network in tumors (Fig. 3A, right panel). Indeed, the VEGF promoter contains estradiol responsive elements which are targets of estradiol/ER and which are inhibited by 4-HT and Faslodex ${ }^{\circledR}$ $[53,54]$ and RU (our unpublished results). Moreover, VEGF induces the anti-apoptotic Mcl-1 up-regulation and protects
MM cells against apoptosis [50]. Thus, the decrease of VEGF in MM cells and in tumors correlates with Mcl-1 decrease or cleavage during RU-induced apoptosis.

Several arguments are in favor of the increased apoptotic effect of RU following its incorporation in liposomes. First, in vitro and as shown in Fig. 5B, a P-gp-like membrane extrusion export of RU may affect the intra-cellular availability of RU necessary for its biological activity. Nevertheless, as RPMI 8226 cell entry of liposomes is suggested to be the consequence of endocytosis (Fig. 5A), it may bypass the P-gp-like detrimental effect. Furthermore, evidence was provided that similar liposomes directly interact with membrane-associated P-gps as shown by their ability to inhibit photoaffinity labeling of the protein [55]. It is possible that in MM cells a strong active export of steroid, mediated by membrane transporters, regulates the intra-cellular concentrations of both $E_{2}$ and $A E$. This feature was described as intervening in binding and export of various steroids in different cells $[29,35,56]$. The presence and high activity level of (a) membrane transporter(s) in MM cells could explain the need of high concentration of $\mathrm{AE}$ to achieve a biological effect. Second, in vivo, the prolonged half-life and the enhanced tumor accumulation of RU-liposomes additive to the in vitro features described above, can all favor the increased intrinsic pro-apoptotic activity of RU. In addition, RU-loaded liposomes display antitumoral activities in MM by two synergistic mechanisms: one triggering apoptosis through the intrinsic (and extrinsic) pathway(s); the other leading to reduction of tumoral angiogenesis. Our studies, therefore, demonstrated that drug delivery systems provide a framework for the use of $\mathrm{AE}$ to improve outcome in MM. In fact, clinical trials from phase I to II of oral tamoxifen administration in MM patients have been previously stopped for high neurotoxicity $[57,58]$. In these trials, tamoxifen was probably not appropriate due to its poor efficacy [14] but it is likely that its administration through drug delivery systems like those described previously [25] and here would have given more encouraging results.

\section{Acknowledgements}

We thank M. Kornprobst for the FACS analysis, M. Pons for MELN cells, P. Van de Velde for the gift of RU 58 668, Dr E. Babin (Service d'ORL, CHU, Caen) for the gift of tonsils and the Service Commun d'Expérimentation Animale of the Institut Gustave Roussy (J. Huard, D. Challuau and P. Ardouin) for technical assistance in animal experimentations. Special thanks are given to J. Mester (Hop St Antoine, Paris) for critical review of the manuscript and discussions and also to J Bréard (INSERM U461, Châtenay-Malabry, France) for support and advices. This study is supported by the Centre National de la Recherche Scientifique, the Université ParisSud, the Ligue Nationale contre le Cancer, [Cher and Indre department comities to J-MR], [Manche department comity to BS], by ARERS-Verre espoir, grant no 273.01, and Fondation de France, grant no 2002004328 to [BS]. 


\section{References}

[1] N.N. Sjak-Shie, R.A. Vescio, J.R. Berenson, Recent advances in multiple myeloma, Curr. Opin. Hematol. 7 (2000) 241-246.

[2] B. Bruno, M. Rotta, L. Giaccone, M. Massaia, A. Bertola, A. Palumbo, M. Boccadoro, New drugs for treatment of multiple myeloma, Lancet Oncol. 5 (2004) 430-442.

[3] S. Nilsson, S. Makela, E. Treuter, M. Tujague, J. Thomsen, G. Andersson, E. Enmark, K. Pettersson, M. Warner, J.A. Gustafsson, Mechanisms of estrogen action, Physiol. Rev. 81 (2001) 1535-1565.

[4] G. Smithson, J.F. Couse, D.B. Lubahn, K.S. Korach, P.W. Kincade, The role of estrogen receptors and androgen receptors in sex steroid regulation of B lymphopoiesis, J. Immunol. 161 (1998) 27-34.

[5] K.L. Medina, A. Strasser, P.W. Kincade, Estrogen influences the differentiation, proliferation, and survival of early B-lineage precursors, Blood 95 (2000) 2059-2067.

[6] L.H. Wang, X.Y. Yang, K. Mihalic, W. Xiao, D. Li, W.L. Farrar, Activation of estrogen receptor blocks interleukin-6-inducible cell growth of human multiple myeloma involving molecular cross-talk between estrogen receptor and STAT3 mediated by co-regulator PIAS3, J. Biol. Chem. 276 (2001) 31839-31844.

[7] D. Chauhan, L. Catley, T. Hideshima, G. Li, R. Leblanc, D. Gupta, M. Sattler, P. Richardson, R.L. Schlossman, K. Podar, E. Weller, N. Munshi, K.C. Anderson, 2-Methoxyestradiol overcomes drug resistance in multiple myeloma cells, Blood 100 (2002) 2187-2194.

[8] T.M. LaVallee, X.H. Zhan, C.J. Herbstritt, E.C. Kough, S.J. Green, V.S. Pribluda, 2-Methoxyestradiol inhibits proliferation and induces apoptosis independently of estrogen receptors alpha and beta, Cancer Res. 62 (2002) 3691-3697.

[9] N. Gao, M. Rahmani, P. Dent, S. Grant, 2-Methoxyestradiol-induced apoptosis in human leukemia cells proceeds through a reactive oxygen species and Akt-dependent process, Oncogene 24 (2005) 3797-3809.

[10] C.K. Osborne, H. Zhao, S.A. Fuqua, Selective estrogen receptor modulators: structure, function, and clinical use, J. Clin. Oncol. 18 (2000) 3172-3186.

[11] R.W. Carlson, The history and mechanism of action of fulvestrant, Clin. Breast Cancer 6 (Suppl. 1) (2005) S5-S8.

[12] P. Narasimhan, Tamoxifen in the treatment of refractory lymphoma, N. Engl. J. Med. 311 (1984) 1258-1259.

[13] S.P. Treon, G. Teoh, M. Urashima, A. Ogata, D. Chauhan, I.J. Webb, K.C. Anderson, Anti-estrogens induce apoptosis of multiple myeloma cells, Blood 92 (1998) 1749-1757.

[14] T. Otsuki, O. Yamada, J. Kurebayashi, T. Moriya, H. Sakaguchi, H. Kunisue, K. Yata, M. Uno, Y. Yawata, A. Ueki, Estrogen receptors in human myeloma cells, Cancer Res. 60 (2001) 1434-1441.

[15] J. Gauduchon, F. Gouilleux, S. Maillard, V. Marsaud, M.J. Renoir, B. Sola, The selective estrogen receptor modulator 4-hydroxy tamoxifen induces G1 arrest and apoptosis of multiple myeloma cell lines, Ann. N.Y. Acad. Sci. 1010 (2003) 321-325.

[16] J. Gauduchon, F. Gouilleux, S. Maillard, V. Marsaud, J.M. Renoir, B. Sola, The 4-hydroxytamoxifen inhibits proliferation of multiple myeloma cells in vitro and in vivo through down-regulation of cMyc, up-regulation of p27Kip1 and modulation of Bcl-2 family members, Clin. Cancer Res. 11 (2005) 2345-2354.

[17] L. Danel, C. Vincent, F. Rousset, B. Klein, R. Bataille, M. Flacher, B.G. Durie, J.P. Revillard, Estrogen and progesterone receptors in some human myeloma cell lines and murine hybridomas, J. Steroid Biochem. 30 (1988) 363-367.

[18] L. Bjornstrom, M. Sjoberg, Mechanisms of estrogen receptor signaling: convergence of genomic and nongenomic actions on target genes, Mol. Endocrinol. 19 (2005) 833-842.

[19] P. Van de Velde, F. Nique, F. Bouchoux, J. Bremaud, M.C. Hameau, D. Lucas, C. Moratille, S. Viet, D. Philibert, G. Teutsch, RU 58,668, a new pure antiestrogen inducing a regression of human mammary carcinoma implanted in nude mice, J. Steroid Biochem. Mol. Biol. 48 (1994) 187-196.
[20] P. Van de Velde, F. Nique, P. Planchon, G. Prevost, J. Bremaud, M.C. Hameau, V. Magnien, D. Philibert, G. Teutsch, RU 58668: further in vitro and in vivo pharmacological data related to its antitumoral activity, J. Steroid Biochem. Mol. Biol. 59 (1996) 449-457.

[21] V. Muller, E.V. Jensen, C. Knabbe, Partial antagonism between steroidal and nonsteroidal antiestrogens in human breast cancer cell lines, Cancer Res. 58 (1998) 263-267.

[22] S. Somai, M. Chaouat, D. Jacob, J.Y. Perrot, W. Rostene, P. Forgez, A. Gompel, Antiestrogens are pro-apoptotic in normal human breast epithelial cells, Int. J. Cancer 105 (2003) 607-612.

[23] J.S. Carroll, D.K. Lynch, A. Swarbrick, J.M. Renoir, B. Sarcevic, R.J. Daly, E.A. Musgrove, R.L. Sutherland, p27(Kip1) induces quiescence and growth factor insensitivity in tamoxifen-treated breast cancer cells, Cancer Res. 63 (2003) 4322-4326.

[24] D.C. Drummond, O. Meyer, K. Hong, D.B. Kirpotin, D. Papahadjopoulos, Optimizing liposomes for delivery of chemotherapeutic agents to solid tumors, Pharmacol. Rev. 51 (1999) 691-743.

[25] T. Ameller, P. Legrand, V. Marsaud, J.M. Renoir, Drug delivery systems for oestrogenic hormones and antagonists: the need for selective targeting in estradiol-dependent cancers, J. Steroid Biochem. Mol. Biol. 92 (2004) 1-18.

[26] T. Ameller, V. Marsaud, P. Legrand, R. Gref, J.M. Renoir, In vitro and in vivo biologic evaluation of long-circulating biodegradable drug carriers loaded with the pure antiestrogen RU 58668, Int. J. Cancer 106 (2003) 446-454.

[27] S. Maillard, T. Ameller, J. Gauduchon, A. Gougelet, F. Gouilleux, P. Legrand, V. Marsaud, E. Fattal, B. Sola, J.M. Renoir, Innovative drug delivery nanosystems improve the anti-tumor activity in vitro and in vivo of anti-estrogens in human breast cancer and multiple myeloma, J. Steroid Biochem. Mol. Biol. 94 (2005) 111121.

[28] X. Troussard, H. Avet-Loiseau, M. Macro, M.P. Mellerin, M. Malet, M. Roussel, B. Sola, Cyclin D1 expression in patients with multiple myeloma, Hematol. J. 1 (2000) 181-185.

[29] F.J. Perez-Victorias, G. Conseil, F. Munoz-Martinez, J.M. PerezVictoria, G. Dayan, V. Marsaud, S. Castanys, F. Gamarro, J.M. Renoir, A. Di Pietro, RU49953: a non-hormonal steroid derivative that potently inhibits P-glycoprotein and reverts cellular multidrug resistance, Cell Mol. Life Sci. 60 (2003) 526-535.

[30] K. Podar, K.C. Anderson, The pathophysiologic role of VEGF in hematologic malignancies: therapeutic implications, Blood 105 (2005) 1383-1395.

[31] V.P. Torchilin, Fluorescence microscopy to follow the targeting of liposomes and micelles to cells and their intracellular fate, Adv. Drug Deliv. Rev. 57 (2005) 95-109.

[32] X. Yan, K. Poelstra, G.L. Scherphof, J.A. Kamps, A role for scavenger receptor B-I in selective transfer of rhodamine-PE from liposomes to cells, Biochem. Biophys. Res. Commun. 325 (2004) 908-914.

[33] G.A. Altenberg, C.G. Vanoye, J.K. Horton, L. Reuss, Unidirectional fluxes of rhodamine 123 in multidrug-resistant cells: evidence against direct drug extrusion from the plasma membrane, Proc. Natl. Acad. Sci. U.S.A. 91 (1994) 4654-4657.

[34] M.M. Gottesman, I. Pastan, Biochemistry of multidrug resistance mediated by the multidrug transporter, Annu. Rev. Biochem. 62 (1993) 385-427.

[35] S. Bourgeois, D.J. Gruol, R.F. Newby, F.M. Rajah, Expression of an mdr gene is associated with a new form of resistance to dexamethasone-induced apoptosis, Mol. Endocrinol. 7 (1993) 840-851.

[36] T.M. Allen, C. Hansen, F. Martin, C. Redemann, A. Yau-Young, Liposomes containing synthetic lipid derivatives of poly(ethylene glycol) show prolonged circulation half-lives in vivo, Biochim. Biophys. Acta 1066 (1991) 29-36.

[37] S.M. Moghimi, J. Szebeni, Stealth liposomes and long circulating nanoparticles: critical issues in pharmacokinetics, opsonization and protein-binding properties, Prog. Lipid Res. 42 (2003) 463-478. 
[38] E.J. Filardo, J.A. Quinn, A.R. Frackelton Jr., K.I. Bland, Estrogen action via the $G$ protein-coupled receptor, GPR30: stimulation of adenylyl cyclase and cAMP-mediated attenuation of the epidermal growth factor receptor-to-MAPK signaling axis, Mol. Endocrinol. 16 (2002) 70-84.

[39] C.M. Revankar, D.F. Cimino, L.A. Sklar, J.B. Arterburn, E.R. Prossnitz, A transmembrane intracellular estrogen receptor mediates rapid cell signaling, Science 307 (2005) 1625-1630.

[40] T. Ameller, V. Marsaud, P. Legrand, R. Gref, G. Barratt, J.M. Renoir, Polyester-poly(ethylene glycol) nanoparticles loaded with the pure antiestrogen RU 58668: physicochemical and opsonization properties, Pharm. Res. 20 (2003) 1063-1070.

[41] M. Gulati, M. Grover, S. Singh, M. Singh, Lipophilic drug derivatives in liposomes, Int. J. Pharm. 165 (1998) 129-168.

[42] M.S. Dilber, M.R. Abedi, B. Bjorkstrand, B. Christensson, G. Gahrton, K.G. Xanthopoulos, C.I. Smith, Suicide gene therapy for plasma cell tumors, Blood 88 (1996) 2192-2200.

[43] M. Cuendet, K. Christov, D.D. Lantvit, Y. Deng, S. Hedayat, L. Helson, J.D. McChesney, J.M. Pezzuto, Multiple myeloma regression mediated by bruceantin, Clin. Cancer Res. 10 (2004) 1170-1179.

[44] F. Yuan, M. Dellian, D. Fukumura, M. Leunig, D.A. Berk, V.P. Torchilin, R.K. Jain, Vascular permeability in a human tumor xenograft: molecular size dependence and cutoff size, Cancer Res. 55 (1995) 3752-3756.

[45] Y. Wang, S. Eksborg, R. Lewensohn, A. Lindberg, E. Liliemark, In vitro cellular accumulation and cytotoxicity of liposomal and conventional formulations of daunorubicin and doxorubicin in resistant K562 cells, Anticancer Drugs 10 (1999) 921-928.

[46] A. Gabizon, D. Papahadjopoulos, Liposome formulations with prolonged circulation time in blood and enhanced uptake by tumors, Proc. Natl. Acad. Sci. U.S.A. 85 (1988) 6949-6953.

[47] G. Pratt, M.E. Wiles, A.C. Rawstron, F.E. Davies, J.A. Fenton, J.A. Proffitt, J.A. Child, G.M. Smith, G.J. Morgan, Liposomal daunorubicin: in vitro and in vivo efficacy in multiple myeloma, Hematol. Oncol. 16 (1998) 47-55.

[48] S.J. Riedl, Y. Shi, Molecular mechanisms of caspase regulation during apoptosis, Nat. Rev. Mol. Cell Biol. 5 (2004) 897-907.

[49] Q. Chen, S. Ray, M.A. Hussein, G. Srkalovic, A. Almasan, Role of Apo2L/TRAIL and Bcl-2-family proteins in apoptosis of multiple myeloma, Leuk. Lymphoma 44 (2003) 1209-1214.
[50] S. Le Gouill, K. Podar, M. Amiot, T. Hideshima, D. Chauhan, K. Ishitsuka, S. Kumar, N. Raje, P.G. Richardson, J.L. Harousseau, K.C. Anderson, VEGF induces Mcl-1 up-regulation and protects multiple myeloma cells against apoptosis, Blood 104 (2004) 2886-2892.

[51] S. Le Gouill, K. Podar, J.L. Harousseau, K.C. Anderson, Mcl-1 regulation and its role in multiple myeloma, Cell Cycle 3 (2004) 1259-1262.

[52] C. Weng, Y. Li, D. Xu, Y. Shi, H. Tang, Specific cleavage of Mcl1 by caspase-3 in tumor necrosis factor-related apoptosis-inducing ligand (TRAIL)-induced apoptosis in Jurkat leukemia T cells, J. Biol. Chem. 280 (2005) 10491-10500.

[53] H. Buteau-Lozano, M. Ancelin, B. Lardeux, J. Milanini, M. PerrotApplanat, Transcriptional regulation of vascular endothelial growth factor by estradiol and tamoxifen in breast cancer cells: a complex interplay between estrogen receptors alpha and beta, Cancer Res. 62 (2002) 4977-4984.

[54] K. Sengupta, S. Banerjee, N. Saxena, S.K. Banerjee, Estradiolinduced vascular endothelial growth factor-A expression in breast tumor cells is biphasic and regulated by estrogen receptor-alpha dependent pathway, Int. J. Oncol. 22 (2003) 609-614.

[55] A. Rahman, S.R. Husain, J. Siddiqui, M. Verma, M. Agresti, M. Center, A.R. Safa, R.I. Glazer, Liposome-mediated modulation of multidrug resistance in human HL-60 leukemia cells, J. Natl. Cancer Inst. 84 (1992) 1909-1915.

[56] V. Marsaud, C. Mercier-Bodard, D. Fortin, S. Le Bihan, J.M. Renoir, Dexamethasone and triamcinolone acetonide accumulation in mouse fibroblasts is differently modulated by the immunosuppressants cyclosporin A, FK506, rapamycin and their analogues, as well as by other P-glycoprotein ligands, J. Steroid Biochem. Mol. Biol. 66 (1998) 11-25.

[57] D.L. Trump, D.C. Smith, P.G. Ellis, M.P. Rogers, S.C. Schold, E.P. Winer, T.J. Panella, V.C. Jordan, R.L. Fine, High-dose oral tamoxifen, a potential multidrug-resistance-reversal agent: phase I trial in combination with vinblastine, J. Natl. Cancer Inst. 84 (1992) $1811-1816$

[58] D. Decaudin, M.C. Etienne, P. De Cremoux, Z. Maciorowski, J.M Vantelon, E. Voog, S. Urien, C. Tran-Perennou, N. Renee, P. Vielh, F. Nemati, P. Pouillart, Multicenter phase II feasibility trial of high-dose tamoxifen in patients with refractory or relapsed multiple myeloma, J. Natl. Cancer Inst. 96 (2004) 636-637. 